\title{
SISTEM LAMPU SEIN MATI OTOMATIS, DETEKSI TITIK BUTA PENGENDARA, DAN ENGINE STOP BERBASIS ARDUINO PADA SEPEDA MOTOR
}

\author{
Fariz Rizkhi Adha ${ }^{1}$, Muhammad Yusro ${ }^{2}$, Pitoyo Yuliatmojo ${ }^{3}$ \\ 1,2,3 Prodi Pendidikan Teknik Elektronika Fakultas Teknik Universitas Negeri Jakarta \\ Email: ${ }^{1}$ farizrizkhiadha@gmail.com, ${ }^{2}$ myusro@unj.ac.id, ${ }^{3}$ pitoyo_y@unj.ac.id
}

\begin{abstract}
Abstrak - Tujuan penelitian ini adalah membuat sistem yang dapat mematikan lampu sein secara otomatis, mendeteksi kendaraan pada area titik buta pengendara, dan engine stop ketika sepeda motor terjatuh berbasis arduino pada sepeda motor. Penelitian ini menggunakan metode penelitian rekayasa teknik yang meliputi desain sistem, perancangan hardware, perancangan software, pengujian hardware dan software, dan analisis pengujian. Sistem yang dirancang pada penelitian ini menggunakan Arduino Nano sebagai mikrokontroller, sensor gyroscope yang dapat mengukur sudut kemiringan sepeda motor saat berbelok dan terjatuh, sensor ultrasonik sebagai pendeteksi jarak kendaraan pada area samping sepeda motor, rangkaian driver relay untuk menyalakan dan mematikan lampu sein serta mematikan mesin ketika terjatuh, LED dan buzzer sebagai indikator jarak kendaraan. Hasil penelitian ini menunjukkan Sistem Lampu Sein Mati Otomatis, Deteksi Titik Buta Pengendara, dan Engine Stop Berbasis Arduino pada Sepeda Motor dapat mematikan lampu sein yang menyala setelah selesai berbelok ke kanan atau kiri, dapat mendeteksi kendaraan atau benda di samping dan memberikan indikator berupa LED yang menyala serta bunyi buzzer sebagai penanda jarak ketika ada kendaraan atau benda yang terdeteksi pada jarak $<=144 \mathrm{~cm}$, dan dapat mematikan mesin jika sepeda motor dalam kemiringan jatuh atau $15^{\circ}$ dari tanah.
\end{abstract}

Kata Kunci: Lampu Sein, Titik Buta Pengendara, Engine Stop, Arduino, Sepeda Motor.

\begin{abstract}
Purpose of this research is to create auto cancelling turn signal lamp, blind spot vehicles detection, and engine stop when crashed system on motorcycle based arduino as the controller. This research uses engineering research methods which includes system design, hardware design, software design, hardware and software testing, and testing analysis. The system designed in this study uses Arduino Nano as the microcontroller, gyroscope sensor to measure the tilt angle of the motorcycle when it turns and falls, the ultrasonic sensor as the detector of the vehicle's distance on the side of the motorcycle, the relay driver circuit to turn on and off the turn signal and stop the engine when falls, LED and buzzer as indicator of vehicle distance. The results of this study indicate the Auto Cancelling Turn Signal Lamp, Blind Spot Detection, and Engine Stop System Based Arduino on Motorcycles can turn off the activated turn signal lamp after turned to the right or left, can detect vehicles or objects on the side and provide an indicator of flashing LED and buzzer's sound as distance markers when any vehicles or objects is detected at distance $<=144 \mathrm{~cm}$, and may shut off the engine if the motorcycle is in a falling angle or $15^{\circ}$ from the ground.
\end{abstract}

Keywords: Turn Signal, Blind Spot, Engine Stop, Arduino, Motorcycle

\section{PENDAHULUAN}

Manusia menciptakan beragam kendaraaan untuk menunjang kualitas hidup dan membantu aktivitas sehari-hari. Di Indonesia kendaraan sepeda motor menjadi pilihan banyak warga sebagai alat transportasi dan jumlah penggunanya pun terus meningkat setiap tahunnya. Namun tidak dapat dipungkiri bahwa penggunaan kendaraan bermotor juga menjadi penyebab utama meningkatnya angka kematian akibat kecelakaan lalu lintas.

Berdasarkan data dari Korps Lalulintas Kepolisian Negara Republik Indonesia pada Gambar 1.1. Grafik Fatalitas Kecelakaan di periode
1 April - 30 Juni 2016 total kasus kecelakaan yang terlapor mencapai lebih dari 20.000 kasus kecelakaan dan korban meninggal dunia yang mencapai 5000 orang. Pada Gambar 1.2. Grafik Jenis Kendaraan di periode yang sama juga terlihat perbandingan jumlah kasus kecelakaan sepeda motor yang mencapai 34.532 kasus kecelakaan, angka tersebut lebih tinggi bila dibandingkan dengan jenis kendaraan lainnya seperti mobil, truk, dan bus.

Berdasarkan data yang direkap dari Korlantas selama tahun 2012, penyebab kecelakaan lalu lintas jalan khususnya sepeda motor paling banyak 
disebabkan oleh faktor Human error sebesar $67 \%$. Sedangkan faktor lainnya, kondisi jalan seperti rusak, bergelombang dan unsur lingkungan misalnya hujan mencapai $33 \%$. Lalu sisanya, seperti kendaraan tak layak jalan $3 \%$ (Republika, 2013). Human error menjadi faktor terbesar penyebab kecelakaan yang dapat terjadi karena tidak mematuhi peraturan lalu lintas, kurangnya konsentrasi hingga berkendara secara ugal-ugalan.

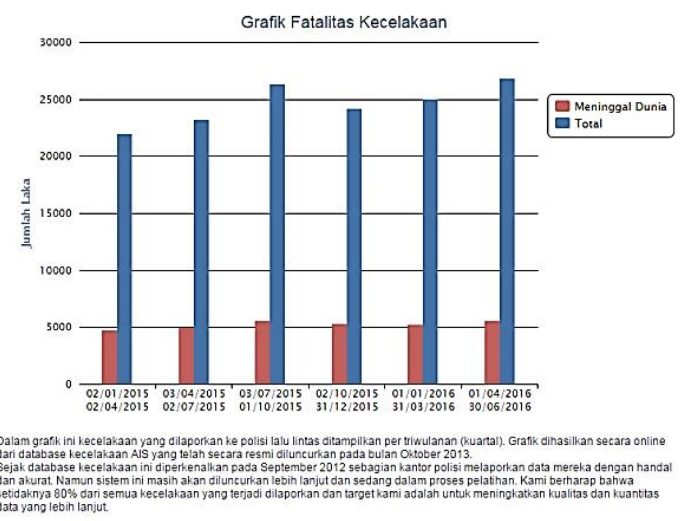

Gambar 1. Grafik Fatalitas Kecelakaan Sumber : (POLRI, 2016)

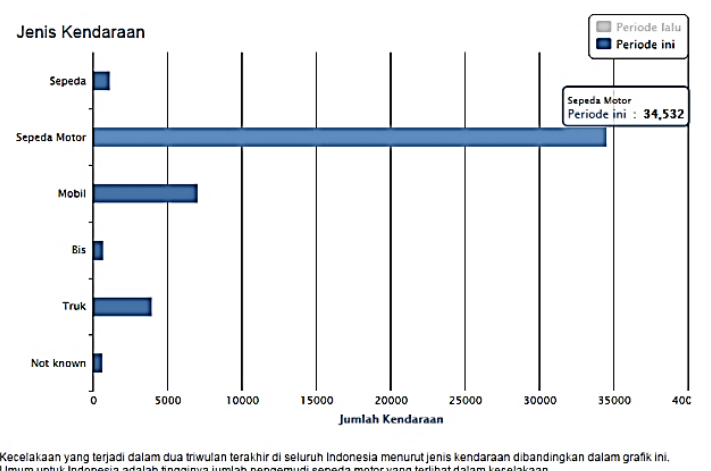

Gambar 1. Grafik Jenis Kendaraan Sumber : (POLRI, 2016)

Tak hanya itu saja, komunikasi antar pengguna jalan pun harus diperhatikan seperti memberi isyarat saat akan berbelok maupun berganti jalur, dalam hal ini merupakan fungsi dari lampu sein, memberikan isyarat lampu sein yang tidak sesuai dengan arah yang kita tuju dan lupa mematikan lampu sein dapat membingungkan pengendara disekitar kita yang dapat mengakibatkan kesalahan komunikasi antar pengendara dan berpotensi pada timbulnya kecelakaan karena bersenggolan. Untuk itu sangat dibutuhkan sistem lampu sein yang dapat mematikan lampu sein secara otomatis apabila isyarat lampu sein yang diberikan tidak sesuai dengan arah yang dituju dan setelah selesai berbelok.
Kecelakaan juga dapat terjadi akibat tidak memperhatikan kendaraan disekitar kita saat akan berbelok atau ketika sedang berganti jalur yang seringkali tidak terlihat dibelakang, terutama di area samping kanan maupun kiri yang tidak terlihat pada kaca spion dan pandangan mata atau disebut juga dengan area titik buta.

Ketika terjadi kecelakaan pun pengendara sepeda motor paling berpotensi untuk mengalami cedera serius dibanding pengendara kendaraan jenis lain. Kondisi ketika terjatuh pun dapat memperburuk keadaan terutama ketika mesin sepeda motor masih menyala dan saat terjatuh tuas gas tertarik sehingga mengakibatkan dampak cedera yang lebih parah terhadap pengendara yang terjatuh maupun pengguna jalan lainnya.

Berlatar belakang masalah - masalah tersebut, diperlukan suatu sistem yang dapat membantu mematikan lampu sein secara otomatis setelah berbelok, membantu mengawasi kendaraan disekitar terutama di area titik buta pengendara dan dapat mematikan mesin kendaraan / engine stop seandainya sepeda motor terjatuh guna meningkatkan keamanan berkendara dan meminimalisir resiko kecelakaan dan cedera yang ditimbulkan bagi pengendara sepeda motor.

\section{METODOLOGI PENELITIAN}

A. Tempat dan Waktu Penelitian

Penelitian skripsi dilakukan di Gedung Teknik Elektro, Fakultas Teknik, Universitas Negeri Jakarta. Penelitian ini dimulai dari Oktober 2016 sampai dengan Juni 2017.

\section{B. Metode Penelitian}

Metode yang digunakan dalam penelitian ini adalah dengan metode rekayasa teknik yang meliputi identifikasi masalah, studi literatur, analisis kebutuhan, desain sistem, perancangan hardware, perancangan software, pengujian hardware dan software, dan analisa pengujian.

\section{HASIL DAN PEMBAHASAN}

Hasil pengujian sensor jarak ultrasonik dengan presentase nilai error sebesar $\pm 0,23 \%$. Pengujian sensor ultrasonik menggunakan program arduino yang telah dibuat sebelumnya. Hasil pengukuran dari sensor ultrasonik merupakan nilai pembulatan, hal tersebut diketahui berdasarkan perbandingan dengan nilai yang didapat dari hasil pengukuran dengan meteran.

Hasil pengujian sensor kemiringan dengan presentase nilai error sebesar $\pm 3,05 \%$. Pengujian sensor kemiringan menggunakan program arduino yang telah dibuat sebelumnya. Sama seperti sensor ultrasonik, hasil pengukuran dari sensor kemiringan merupakan nilai pembulatan, hal tersebut diketahui 
berdasarkan perbandingan dengan nilai yang didapat dari hasil pengukuran dengan busur derajat.

Pengujian rangkaian lampu sein mati otomatis telah sesuai dengan konsep dan program arduino yang dibuat. Saat tombol lampu sein kanan dan kiri ditekan dapat mengaktifkan relay input relay dan selanjutnya mengaktifkan output relay untuk menyalakan lampu sein sepeda motor. Dalam pengujian tombol lampu sein off, tombol lampu sein off ditekan setelah menekan tombol lampu sein kanan atau kiri. Dari pengujian tersebut tombol lampu sein off dapat menonaktifkan input dan output dari relay ketika ditekan sehingga lampu sein tidak menyala, sedangkan ketika tidak ditekan lampu tetap menyala.

Hasil pengujian lampu sein mati otomatis dengan tiga kriteria pengujian yaitu,

1. Menyalakan lampu sein dan mematikan lampu lein setelah berbelok ke kanan, dari 10 kali hasil pengujian didapatkan nilai tingkat keberhasilan $100 \%$.

2. Menyalakan lampu sein dan mematikan lampu lein setelah berbelok ke kiri, dari 10 kali hasil pengujian didapatkan nilai tingkat keberhasilan $100 \%$.

3. Menyalakan lampu sein dan mematikan lampu sein setelah tidak berbelok selama 5 detik, dari 10 kali hasil pengujian didapatkan nilai tingkat keberhasilan $100 \%$.

Hasil pengujian sistem lampu sein mati otomatis berjalan sesuai dengan fungsinya, dan telah sesuai dengan pogram arduino yang dibuat dengan tingkat keberhasilan setiap kondisi sebesar 100\%.

Hasil pengujian tingkat keberhasilan deteksi titik buta pengendara telah sesuai dengan kriteria yang ditentukan. Indikator jarak LED dan buzzer aktif ketika ada benda atau kendaraan yang terdeteksi pada jarak $<=144 \mathrm{~cm}$. Dari hasil yang didapat diketahui hasil pengujian deteksi titik buta pengendara sesuai dengan fungsinya.

Hasil pengujian tingkat keberhasilan engine stop telah sesuai dengan kriteria yang ditentukan. Mesin sepeda motor mati ketika terdeteksi kemiringan sepeda motor sebesar $1^{\circ}, 10^{\circ}, 170^{\circ}$, dan $180^{\circ}$. Dari hasil yang didapat diketahui hasil pengujian engine stop ketika sepeda motor pada kemiringan terjatuh yaitu $15^{\circ}$ dari tanah telah sesuai dengan kriteria keberhasilan.

Hasil pengujian LCD telah sesuai dengan program arduino yang dibuat. Tampilan pada LCD menampilkan hasil pengukuran jarak sensor ultrasonik kanan, hasil pengukuran jarak sensor ultrasonik kiri, dan hasil pengukuran kemiringan sensor gyroscope.

Dari pengujian berbagai sub sistem diketahui sistem lampu sein mati otomatis, deteksi titik buta / blind spot pengendara dan engine stop telah sesuai dengan fungsinya dan dapat berjalan secara bersamaan.

\section{KESIMPULAN}

Pengujian sistem yang telah dirancang pada sepeda motor dilakukan berdasarkan kriteria pengujian yaitu, dapat mematikan lampu sein yang telah dinyalakan secara otomatis setelah berbelok, mendeteksi adanya kendaraan atau benda pada area blind spot / titik buta pengendara, dan mematikan mesin kendaraan / engine stop ketika terjatuh berbasis arduino pada sepeda motor. Dari pengujian yang telah dilakukan menghasilkan:

1. Sistem lampu sein mati otomatis dapat mematikan lampu lein yang menyala setelah berbelok ke kanan, mematikan lampu lein yang menyala setelah berbelok ke kiri, dan mematikan lampu sein yang menyala setelah tidak berbelok selama 5 detik dengan tingkat keberhasilan setiap kondisi sebesar $100 \%$.

2. Sistem deteksi titik buta / blind spot pengendara dapat mendeteksi kendaraan atau benda disamping dan memberikan indikator berupa LED yang menyala dan bunyi penanda jarak ketika ada kendaraan atau benda yang terdeteksi pada jarak $<=144 \mathrm{~cm}$.

3. Sistem engine stop saat sepeda motor terjatuh dapat mematikan mesin jika sepeda motor dalam kemiringan jatuh atau $15^{\circ}$ dari tanah.

Dari pengujian yang telah dilakukan, dapat disimpulkan bahwa hasil pengujian sistem yang dibuat telah memiliki spesifikasi sesuai dengan kriteria pengujian.

\section{REFERENSI}

[1] Anggraini, D. (2010). Aplikasi Mikrokontroler ATMEGA16 Sebagai Pengontrol Sistem Emergency dan Lampu Jalan yang Dilengkapi dengan Sensor Cahaya (LDR) pada Miniatur Kompleks Perumahan Modern. Universitas Diponegoro.

[2] Arduino. (2009). Arduino - ArduinoBoardNano. Diambil 21 Oktober 2016, dari https://www.arduino.cc/en/Main/ArduinoBoardNano

[3] Arduino. (2017). MPU6050. Diambil 9 Maret 2017, dari http://playground.arduino.cc/Main/MPU-6050\%0A

[4] Atmika, I. K. A., Subagia, I. D. G. A., Sutantra, I. N., \& Pramono, S. (2008). Simulation of Motorcycle Smart Handling With Addition Gyroscopic Component, 20(2), 5763.

[5] Aziz, A. S. (2014). Implementasi Sensor Accelerometer MMA 7361 sebagai Pengaman pada Sepeda Motor Matic untuk Meminimalisir Dampak Kecelakaan. Universitas Brawijaya, 1-7.

[6] Fakultas Teknik. (2015). Buku Panduan Penyusunan Skripsi dan Non Skripsi. Jakarta: Fakultas Teknik, Universitas Negeri Jakarta.

[7] Hutahean, J. (2014). Konsep Sistem Informasi (1 ed.). Yogyakarta: Deepublish.

[8] Indoware. (2013). Ultrasonic Ranging Module HC - SR04. Datasheet, 1-4. Diambil dari http://www.micropik.com/PDF/HCSR04.pdf

[9] InvenSense Inc. (2013). MPU-6000 and MPU-6050 Product Specification Revision 3.4, 1(408). 
[10] Jatmiko, P. (2015). PLC ,HMI and Industrial part: PLC ,HMI and Industrial part Volume 1 of INDUSTRI 1 (1 ed.). Bogor: Kartanagari.

[11] Jogiyanto, H. (2005). Analisis dan Desain (1 ed.). Yogyakarta: Andi Offset.

[12] Kelly, B. P., State, C., Agency, T., \& Shiomoto, J. (2016). California Motorcycle Handbook, 60.

[13] Law, T. H. (2005). Determination of Comfortable Safe Width in an Exclusive Motorcycle Line. Journal of the Eastern Asia Society for Transportation Studies, 6, 33723385.

[14] Magdalena, G., Aribowo, A., \& Ati Halim, F. (2013). Perancangan sistem akses pintu garasi otomatis menggunakan platform Android. Prosiding Conference on Smart-Green Technology in Electrical and Information System, D-025(November), 301-306.

[15] Marimin. (2004). Teknik dan Aplikasi Pengambilan Keputusan Kriteria Majemuk. Jakarta: Grasindo.

[16] POLRI, K. (2016). ACCIDENT COUNT: Grafik Fatalitas Kecelakaan. Diambil 20 Oktober 2016, dari http://korlantasirsms.info/graph/accidentData

[17] Prawiroredjo, K., \& Asteria, N. (2008). Detektor Jarak dengan Sensor dengan Sensor Mikrokontroler. JETri, 7, 4152 .

[18] Priyatno, D. (2015). Panduan Lengkap Komputer: PC, Laptop, Tablet. Jakarta: Puspa Swara.

[19] Sagita, M. (2015). Aplikasi LED RGB pada Lengan Robot Penyortir Kotak Berdasarkan Warna Berbasis Arduino Uno. Politeknik Negeri Sriwijaya. Diambil dari http://eprints.polsri.ac.id/id/eprint/1810

[20] Sena, S. A., Muttaqin, A., \& Setyawan, A. (2013). Perancangan dan Pembuatan Application Interface Server untuk Arduino, 6. Diambil dari http://elektro.studentjournal.ub.ac.id/index.php/teub/article/ download/112/79

[21] Soedarmo, H. (2008). Panduan Praktis Merawat \& Memperbaiki Sepeda Motor. Jakarta: Gramedia Pustaka Utama.

[22] TDK. (2008). Piezoelectronic Buzzers ( without circuit ) PS Series ( Pin Terminal / Lead ), (July), 1-7. Diambil darì http://tronixstuff.com/wpcontent/uploads/2010/07/ps1240_datasheet.pdf

[23] Varghese, B., Jacob, R. T., Kamar, F., \& Saifudeen, R. A (2014). Collision Avoidance System in Heavy Traffic and Blind Spot Assist Using Ultrasonic Sensor, 2(1), 93-96.

[24] Wangsadinata, W., Suprayitno, G., \& Roosseno, H. (2008). Roosseno: Jembatan dan Menjembatani. Jakarta: Yayasan Obor Indonesia.

[25] Wicaksana, C. (2016). Perancangan Alat Penetral Lampu Sein Sepeda Motor Otomatis Berbasis Arduino R3. ITEKS Intuisi Teknologi dan Seni, 8(1), 65-72. 